\title{
Microbiological analysis of acute infections of the nail fold on the basis of bait thread test
}

\author{
Hanna Tomczak ${ }^{1}$ Aleksandra Dańczak-Pazdrowska², Adriana Polańska³, Agnieszka Osmola-Mańkowska², \\ Jakub Pazdrowski ${ }^{4}$, Wioleta Błażejewska-Gąsior ${ }^{1}$, Anna Horla' ${ }^{1}$, Marta Hasse-Cieślińska², Zygmunt Adamski ${ }^{2}$
}

${ }^{1}$ Central Microbiological Laboratory, Święcicki University Hospital, Poznan, Poland

2Department of Dermatology, Poznan University of Medical Sciences, Poznan, Poland

${ }^{3}$ Department of Dermatology and Venereology, Poznan University of Medical Sciences, Poznan, Poland

${ }^{4} \mathrm{Head}$ and Neck Surgery Ward, Laryngological Oncology Clinic, Poznan University of Medical Sciences, Poznan, Poland

Adv Dermatol Allergol 2017; XXXIV (2): 110-115

DOI: https://doi.org/10.5114/ada.2017.67072

\begin{abstract}
Introduction: An acute infection of the nail fold, called paronychia, is a common clinical problem. The basis for the implementation of the treatment is the result of microbiological examination. Due to the rapid and painful course of infection, usually an empirical antimicrobial treatment prior to obtaining microbiological test results is introduced. Aim: The microbial analysis of acute infections of the nail fold.

Material and methods: The study included 32 tests conducted on 31 patients of the Department of Dermatology. Microbiological analysis was performed with the use of the so-called bait thread test.

Results: In 73\% of analyzed cases microbiological examination revealed mixed microbiological flora. Most cultured microorganisms were: Enterococcus faecalis (14\%), Staphylococcus aureus (12\%), Candida albicans (9\%), Enterobacter cloacae (8\%), and Klebsiella pneumoniae (7\%). Most cultured bacteria belonged to the families or genera of Enterobacteriaceae (36\%), other cultured bacteria were staphylococci (26\%), enterococci (16\%), Candida species (14\%), and Gram-negative non-fermenting bacilli (8\%).

Conclusions: The acute infection of the nail fold in the vast majority of cases is caused by mixed bacterial flora. A profile of isolated microorganisms suggests that the cause of the infection can be associated with neglect of hygiene. Fluoroquinolone and fusidic acid are recommended as the empirical therapy. Microbiological examination is the basis for the appropriate final treatment.
\end{abstract}

Key words: paronychia, nail fold, infection, Enterobacteriaceae, staphylococci, bait thread test.

\section{Introduction}

Acute infection of the nail fold, called paronychia, is a common clinical problem. From the dermatological point of view it is characterized by the presence of erythema, swelling and pain, which mostly are observed within the dominant hand, particularly the thumb or index finger. In most of cases it is caused by infection. This infection may result from minor injuries like nail biting, finger sucking or aggressive manicuring. Very important risk factors include diabetes mellitus and exposure to moisture conditions in a workplace. Therefore, cooks, laundresses, housekeepers and physical workers (mostly in rural areas) are specially predisposed to paronychia [1-6]. Table 1 summarizes the possible diseases/condi- tions and occupations associated with an increased tendency to paronychia [7]. The basis for the implementation of the treatment is a result of microbiological examination of the swab obtained from the nail fold. However, it should be noted that not always purulent discharge from the nail plate is detected [2]. In such circumstances, the recommended examination is the use of a so-called bait thread test $[7,8]$. Bait thread test was introduced by Alkiewicz (world famous Polish mycologist) to detect nail fold yeast infections. In this test the cotton sterile thread, which is soaked with Sabouraud broth, is placed underneath the nail fold for $24 \mathrm{~h}$. After removing, thread is cultured $[9,10]$.

Due to the rapid and painful course of infection, usually prior to obtaining microbiological test results, an

Address for correspondence: Aleksandra Dańczak-Pazdrowska MD, PhD, Department of Dermatology, Poznan University of Medical Sciences, 49 Przybyszewskiego St, 60-355 Poznan, Poland, phone: +48 61869 12 85, fax: +48 6186915 72,

e-mail: aleksandra.pazdrowska@onet.eu

Received: 30.05.2015, accepted: 14.02.2016. 
empirical antimicrobial treatment is introduced. What is more, this is desirable as the infection may continue to spread and involve the tendons or deep spaces of the hand, leading even to the amputation of the phalanx [11].

\section{Aim}

Therefore, the aim of this study was the analysis of microbial infections of the nail fold based on the socalled bait thread test in patients treated in the Department of Dermatology, Poznan University of Medical Sciences.

\section{Material and methods}

Microbiological analysis was performed with the use of the so-called bait thread test at the Central Laboratory of Microbiology in Święcicki University Hospital in Poznan in 2006-2011. This method was previously described in the literature by Alkiewicz and was based on the localization of the sterile thread soaked in Sabouraud broth underneath the nail fold for several hours [8-10, 12].

The study included 32 tests conducted on patients of the Department of Dermatology, University of Medical Sciences in whom, on the basis of the clinical picture, acute nail fold infection was suspected (Figure 1). In 2 cases ( 2 women), the results were negative - no growth of the pathogenic flora. The remaining 30 studies were taken from 29 patients ( 24 women, 5 men) and revealed
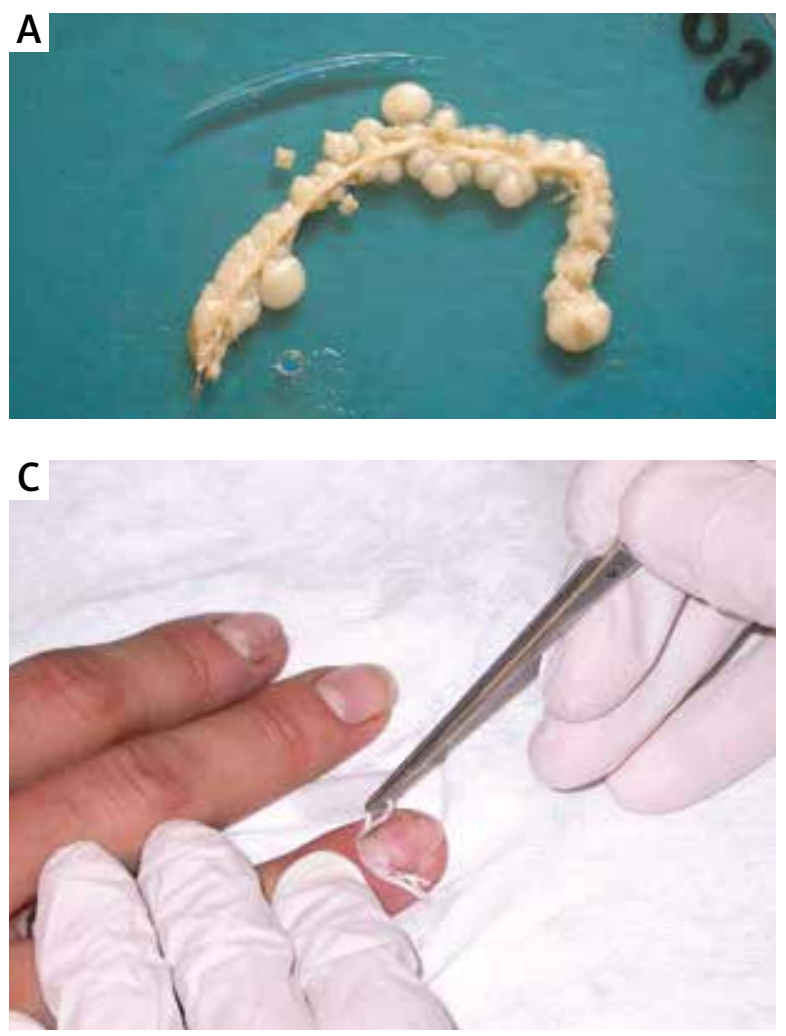

Table 1. The list of different diseases/conditions and occupations with a higher risk of paronychia (on the basis of $[5,7])$

\begin{tabular}{ll}
\hline Diseases/conditions & Occupations \\
\hline Celiac disease & Hairdressers \\
\hline Chronic lymphocytic leukemia & Bartenders \\
\hline Diabetes mellitus & Builders \\
\hline Frostbite & Cooks \\
\hline Histiocytosis X & Cosmetologists \\
\hline Hypoparathyroidism & Dentists \\
\hline Progressive systemic sclerosis & Farmers \\
\hline Psoriasis & Fishermen \\
\hline Raynaud's disease & Housewives \\
\hline Retinoids & Meat/raw food handlers \\
\hline Stevens-Johnson syndrome & Mechanics \\
\hline Systemic lupus erythematosus & Pianists \\
\hline Traumatic injury & Waitresses/waiters \\
\hline Pemphigus & Masseurs \\
\hline
\end{tabular}

the presence of the pathogenic flora. From 1 patient (male) the material was collected twice.

Each thread obtained from the patient was then placed in the broth medium in a tube $(\mathrm{BHI}$ - brain-heart broth, bioMerieux) for initial proliferation. After $24 \mathrm{~h}$ of

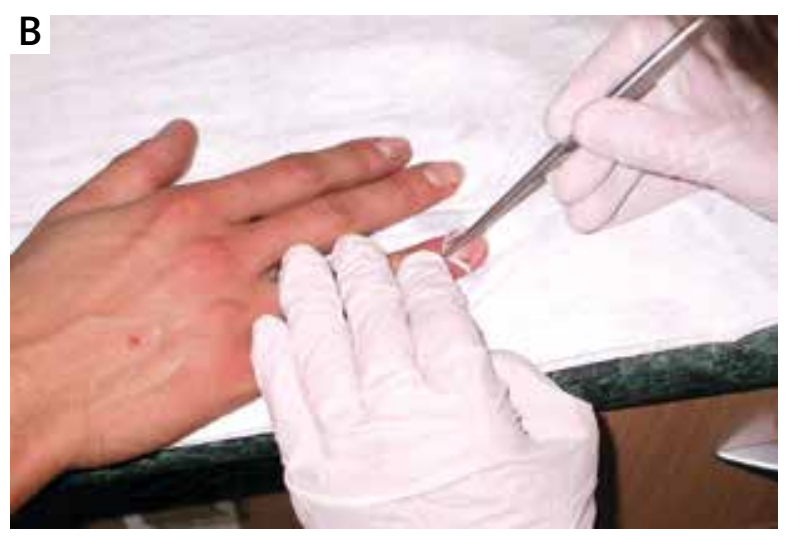

Figure $1 \mathrm{~A}, \mathrm{~B}, \mathrm{C}$. Bait thread test 
incubation, broth was cultured on solid media (bioMerieux): Columbia agar with 5\% blood, MacConkey's agar, Chapman Agar, D-coccosel Agar, Sabouraud agar with gentamicin and chloramphenicol. Cultured material was incubated under aerobic conditions in an incubator at $37^{\circ} \mathrm{C}$ for $24 \mathrm{~h}$. Due to the absence of microbial growth on the first day after first culture, the cultivation time was extended to $48 \mathrm{~h}$. After the period of incubation, $24 \mathrm{~h}$ for bacteria, $48 \mathrm{~h}$ for yeast, reading and further isolations were made. Finally the identification and assessment of the sensitivity to antibiotics or antifungal agents were performed. Identification of microorganisms was carried out using the bioMerieux VITEK system and bioMerieux ATB. Evaluation of sensitivity to antibiotics was performed in the automatic VITEK system. Organisms were also examined for the presence of resistance mechanisms.

\section{Results}

In the analyzed material 74 microorganisms were isolated. Pathogens were isolated from 30 tested threads. In 2 cases no microorganisms were cultured. The number of grown pathogens in 1 material ranged from 1 to 5 species, but only in 8 (27\%) cases single microorganisms were isolated: Staphylococcus (Staph.) aureus (4 patients), Enterococcus faecalis (2 patients), Klebsiella pneumonia (1 patient), and Escherichia coli (1 patient). In the remaining tests mixed flora was found (Figure 2).

The most common cultured organisms were (in the following order): Enterococcus faecalis - 10× (14\%), Staph. aureus - 9× (12\%), Candida albicans - 7× (9\%), Enterobacter cloacae - 6× (8\%), Klebsiella pneumonia - 5× (7\%), and Staph. haemolyticus - 4× (5\%) (Figure 3).

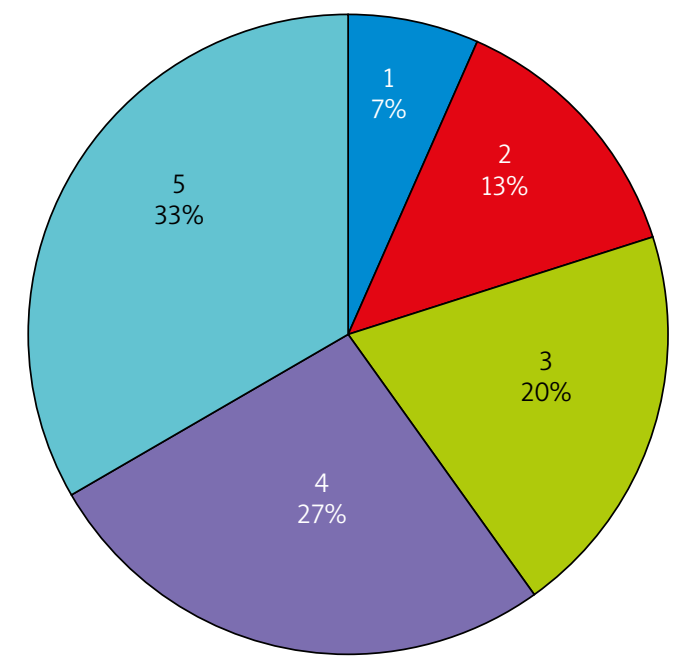

Figure 2. Number of pathogens isolated from one sample
Sorting cultured microorganisms according to their family or genera (in the following order), Enterobacteriaceae $-27 \times(36 \%)$, staphylococci $-19 \times(26 \%)$, enterococci $-12 \times(16 \%)$, Candida species (spp.) $-10 \times(14 \%)$, and Gram-negative non-fermenting bacilli $-6 \times(8 \%)$ were detected (Figure 4). Among the Enterobacteriaceae family the following species were isolated: Enterobacter cloacae - 6× (22\%), Klebsiella pneumoniae - 5× (18\%), Escherichia coli $-3 \times(11 \%)$, Serratia marcescens $-3 \times(11 \%)$, Morganella morganii $-2 \times(7 \%)$, Citrobacter freundii $2 \times(7 \%)$, Klebsiella oxytoca $-2 \times(7 \%)$, Proteus mirabilis $2 \times(7 \%)$, Citrobacter braakii $-1 \times(4 \%)$, Providencia rettgeri$1 \times(4 \%)$ (Figure 5). Among staphylococci: Staph. aureus $9 \times(47 \%)$, Staph. haemolyticus $-4 \times(21 \%)$, Staph. warneri $-3 \times(16 \%)$, Staph. saprophyticus - 1× (5\%), Staph. epidermidis - 1× (5\%), and Staph. lugdunensis - 1× (5\%) (Figure 6). Among enterococci: Enterococcus faecalis - 10× (83\%), Enterococcus faecium - 1× (8\%), Enterococcus avium $1 \times(8 \%)$. Among fungi: Candida albicans - 7× (70\%) and Candida parapsilosis - 3× (30\%). Among Gram-negative non-fermenting bacilli: Pseudomonas aeruginosa$3 \times(50 \%)$, Acinetobacter Iwoffii - $2 \times(33 \%)$, and Acinetobacter baumanii - $1 \times(17 \%)$.

Fungi of the genus Candida were isolated in 10 cases, representing $14 \%$ of the studies. These have always appeared together with 2-4 other pathogens, never as a single pathogen.

Among the strains of Enterobacteriaceae family all isolated strains were susceptible to most antibiotics (multisusceptible microorganisms), that were probably

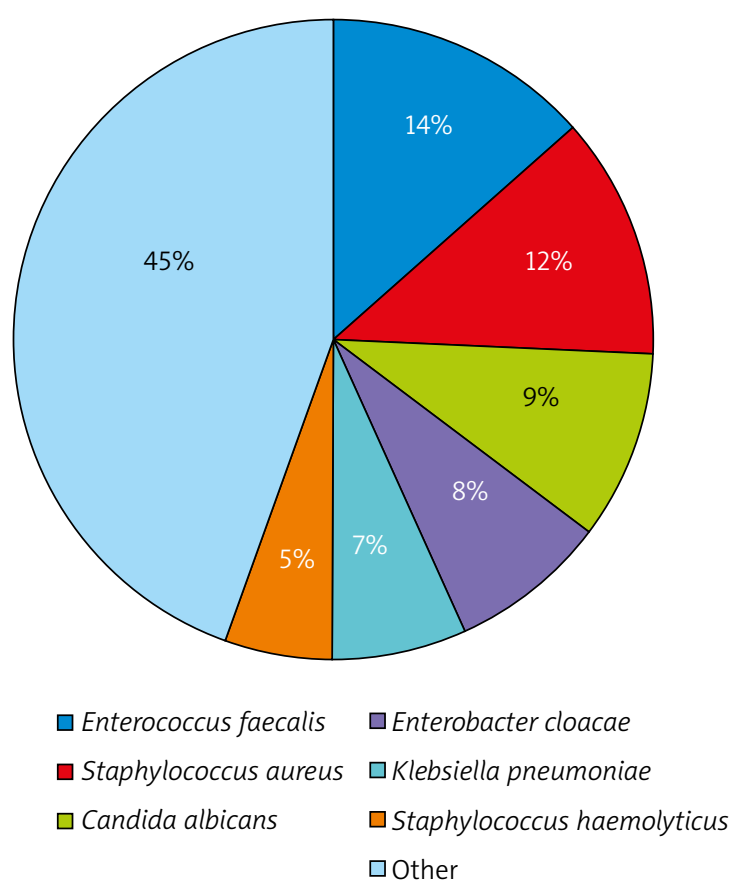

Figure 3. Most commonly isolated pathogens 
own strains, the so-called wild. Twenty seven strains were cultured and analyzed. All analyzed strains were sensitive to amikacin, ciprofloxacin, second generation of cephalosporins - cefoxitin, third and fourth generation of cephalosporins (cefotaxime, ceftriaxone, cefepime), piperacillin/tazobactam, carbapenems (imipenem and meropenem), ticarcillin/clavulan acid. 96\% were sensitive to gentamicin and trimethoprim/sulfamethoxazole, $63 \%$ to ampicillin/sulbactam or amoxicillin/clavulan acid, 40\% to cephalothin (first-generation cephalosporin), 20\% to cefazolin (first-generation cephalosporin) and 19\% to ampicillin.

Among staphylococci, Staph. aureus revealed 100\% sensitivity to fusidic acid, chloramphenicol, rifampicin, trimethoprim/sulfamethoxazole, gentamicin, vancomycin, teicoplanin, $88 \%$ to ofloxacin (representing quinolones), $77 \%$ to clindamycin and tetracycline, $62 \%$ to fosfomycin, and $44 \%$ to erythromycin. Coagulase-negative staphylococci (Staph. haemolyticus, Staph. warneri, Staph. saprophyticus, Staph. epidermidis) and Staph. lugdunensis demonstrated $100 \%$ sensitivity to rifampicin and vancomycin, $90 \%$ to trimethoprim/sulfamethoxazole, $88 \%$ to ofloxacin, $80 \%$ to lincomycin (clindamycin), $60 \%$ to tobramycin, $50 \%$ to erythromycin and fusidic acid and $30 \%$ to teicoplanin.

Susceptibility of enterococci was as follows: $100 \%$ sensitive to linezolid, moxifloxacin (representing quinolones), vancomycin, levofloxacin, 92\% to penicillin, 75\% to gentamycin, and 30\% to tetracycline.

All cultured Candida were susceptible to amphotericin B and 5-fluorocytosine, $70 \%$ to fluconazole, and 60\% to itraconazole and voriconazole.

All Gram-negative non-fermenting bacilli were sensitive to gentamicin, imipenem, meropenem, ceftazidime, cefepime, ciprofloxacin, 83\% to ampicillin/sulbactam,

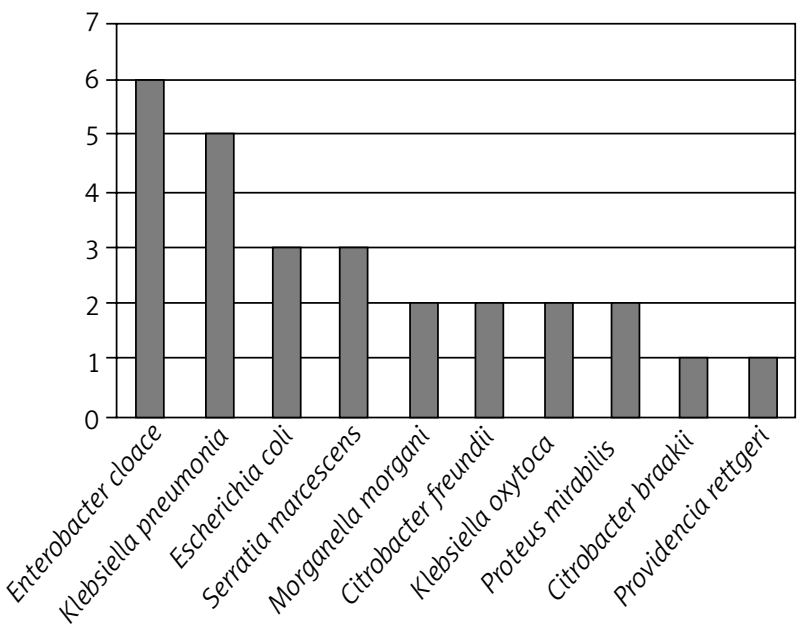

Figure 5. Most commonly isolated species from the Enterobacteriaceae family

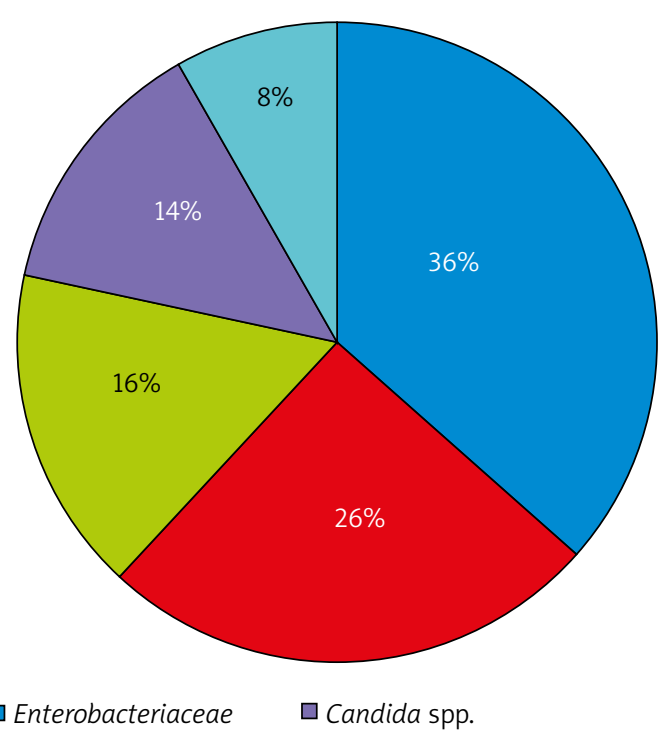

$\square$ Staphylococci

$\square$ Enterococci

$\square$ Gram-negative non-fermenting bacilli

Figure 4. Most commonly isolated pathogens' families or genera

additionally all presented resistance to trimethoprim/ sulfamethoxazole.

\section{Discussion}

Paronychia is one of the most frequently observed localized hand infections, which clinically can be divided into an acute and chronic form [3]. The acute type of infection usually arises spontaneously as a result of bacterial growth due to the different trauma. This form

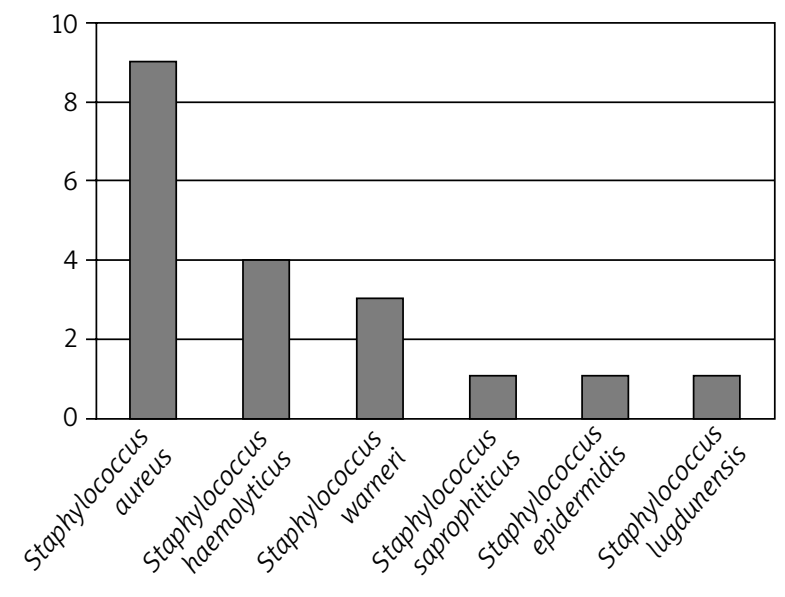

Figure 6. Most commonly isolated species from the Staphylococci genus 
is associated with intense pain and tenderness of perionychium, provoked by collection of pus. On the other hand, the chronic type is more often detected among patients, who are continuously exposed to moist conditions, like bartenders, housekeepers, homemakers, dishwashers and swimmers (Table 1) [3, 7, 13-15]. Its cause is multi-factorial and includes Candida, low-grade bacterial infection, prolonged contact with contactants and irritants. From the clinical point of view, nail plates become thickened and discolored, the cuticle is reddened and pain is not so intense like in the acute form. It has to be underlined that in patients with recurrent infection, fungal infection should be always considered [3, 7].

In the presented material, nail fold infection was more frequently observed among women, which is confirmed in the literature [5, 12]. Usually mixed infections caused by 2 to 5 different pathogens were observed (73\% of the samples), similarly to previous studies $[1,16]$. In $27 \%$ (8 cases), the infection was caused by one pathogen. Then Staph. aureus (4 patients), Enterococcus faecalis (2 patients), Klebsiella pneumonia (1 patient), and Escherichia coli (1 patient) were isolated.

Among the most frequently isolated families or genera are the following: Enterobacteriaceae (representing $36 \%)$, staphylococci (26\%), enterococci (16\%), Candida sp. (14\%), and Gram-negative non-fermenting bacilli (8\%). In the literature, among the more commonly indicated pathogens are enterococci, Enterobacteriaceae, Staphylococcus and Gram-negative non-fermenting bacilli [2, 16]. The most common infectious pathogen is Staph. aureus $[3,4,17]$. Rarely cultured bacteria are anaerobic ones [11]. Among them Gram-positive cocci, Bacteroides spp. and Fusobacterium spp. are the most frequent [16]. It has to be stressed that in all study cases coagulasenegative staphylococci were isolated as a component of mixed flora. It is unclear whether they play a real role in paronychia or they are just contaminants. However methicillin-resistant strains should be considered as pathogenic. Moreover, coagulase-negative staphylococci can form biofilm and for example they can be responsible for catheter-related bloodstream infection [18]. The bacterial flora detected in our study is largely typical for the anogenital area. Similar results were observed by Iranian researchers [1].

Fungi of the genus Candida were isolated only in $14 \%$ of samples. Rare presence of yeast in nail fold infection was also noted by other authors [16]. In addition, it should be emphasized that none of our results suggested that fungi of the genus Candida are the single pathogen. In all cases they were a component of mixed fungobacterial infection. Additionally, the number of accompanied bacterial pathogens ranged from 2 to 4 . Among fungal infections, the most frequently isolated fungi were Candida albicans, and then Candida parapsilosis, which was confirmed in previous reports [12]. In the literature there are also descriptions of other species of the genus Can- dida, which may be occasionally a pathogenic factor in the nail fold infections, including Candida guilliermondii, Candida glabrata, Candida tropicalis and Candida kefyr $[1,12]$. They were not isolated in this study.

Microbiological analysis of sensitivity to antibiotics indicates usefulness of fluoroquinolones (ciprofloxacin, ofloxacin, moxifloxacin, levofloxacin) in the treatment of paronychia because 100\% of the isolated Enterobacteriaceae were enterococci and Gram-negative non-fermenting bacilli and $88 \%$ staphylococci were sensitive to them. However, the latter were in $100 \%$ sensitive to topical use of fusidic acid. This is an important issue in clinical practice, when a decision on empiric antibiotic therapy prior to obtaining a result of microbiological culture is made. The effectiveness of fluoroquinolones was also pointed by Eames et al. [19]. Importantly, the authors based their opinion on the microbiological analysis. These findings differ from the recommendations found in two papers of Rigopoulos et al. and Rockwell, who assumed that oral antibiotics should have primary antistaphylococcal action and suggested the use of amoxicillin with clavulanic acid, clindamycin and trimethoprim with sulfamethoxazole $[3,4]$. Our analysis of susceptibility revealed that these drugs in empiric antibiotic therapy are not justified. On the other hand, among antifungal agents nystatin appears to be useful. This drug belongs to the same group as amphotericin B, which showed sensitivity of $100 \%$ of the tested strains. It should be noted that in this analysis, sensitivity of Candida spp. to fluconazole and itraconazole was only $70 \%$ and $60 \%$, respectively. Due to the significant toxicity of these agents, one should therefore refrain from a decision on their inclusion until the result of the evaluation of their sensitivity is obtained.

To sum up, it should be emphasized that the acute infection of the nail fold in the vast majority of cases is a mixed flora infection. A profile of isolated microorganisms suggests that the cause of the infection in many cases can be associated with neglect of hygiene. Most frequently isolated bacteria belong to the Enterobacteriaceae, followed by staphylococci. For this reason, the preferred empirical treatment is a combination of fluoroquinolone and fusidic acid. The basis for the appropriate treatment is properly performed microbiological examination with the evaluation of susceptibility [20]. Due to the possibility of different etiological factors for infections with different resistance formula, there is a need to conduct periodic microbiological analyses on larger groups of subjects in a variety of environments.

\section{Conclusions}

Paronychia is an important clinical problem, which usually affects women. The bait thread test is a useful diagnostic tool to detect causative agents of paronychia. Mixed flora (including Enterobacteriaceae and staphylococci) is responsible for most cases of nail fold infections. 
Proposed empirical treatment of paronychia should include a combination of fluoroquinolone and fusidic acid. Neglect of hygiene is a risk factor for paronychia.

\section{Conflict of interest}

The authors declare no conflict of interest.

\section{References}

1. Thappa DM, Kumari R, Singh R, et al. Evaluation of role of Candida in patiants with chronic paronychia. Indian J Dermatol Venereol Leprol 2015; 81: 485-90.

2. Baran E. Wybrane choroby paznokci. Przew Lek 2000; 6: 67-70.

3. Rockwell PG. Acute and chronic paronychia. Am Fam Phys 2001; 63: 1113-6.

4. Rigopoulos D, Larios G, Gregoriou S, Alevizos A. Acute and chronic paronychia. Am Fam Physician 2008; 77: 339-46.

5. Durdu M, Ruocco V. Clinical and cytologic features of antibiotic-resistant acute paronychia. J Am Acad Dermatol 2014; 70: 120-6.

6. Chang P. Diagnosis using the proximal and lateral nail folds. Dermatol Clin 2015; 33: 207-41.

7. Daniel CR 3rd. Diagnosis of Onychomycosis and Other Nail Disorders. A pictorial atlas. Springer, New York, 1996.

8. Hasse-Cieślińska M. Diagnostyka i leczenie powierzchownych zakażeń grzybiczych. Przew Lek 2006; 7: 109-20.

9. Adamski Z, Batura-Gabriel H. Mikologia lekarska dla lekarzy i studentów. Uniwersytet Medyczny im. K. Marcinkowskiego w Poznaniu, Poznan 2007.

10. Prochacki H. Podstawy mikologii lekarskiej. PZWL, Warsaw 1975.

11. Riesbeck K. Paronychia due to Prevotella bivia that resulted in amputation: fast and correct bacteriological diagnosis is crucial. J Clin Miocrobiol 2003; 41: 4901-3.

12. Krzemińska-Jaśkowiak E, Dembińska M, Cybulski Z, et al. Grzybicza i bakteryjna flora wałów paznokciowych u pacjentów z wieloogniskowym zakażeniem Candida spp. Mikol Lek 2003; 10: 249-53.

13. Hochman LG. Paronychia: more than just an abscess. Int J Dermatol 1995; 34: 385-6.

14. Jebson PJ. Infections of the fingertip. Paronychias and felons. Hand Clin 1998; 14: 547-55.

15. Jules KT, Bonar PL. Nail infections. Clin Podiatr Med Surg 1989; 6: 403-16.

16. Brook I. Aerobic and anaerobic microbiology of paronychia. Ann Emerg Med 1990; 19: 994-6.

17. Maleszka R, Ratajczak-Stefańska V, Różewicka-Czabańska M. Zmiany infekcyjne paznokci. Przegl Dermatol 2011; 98: 120-7.

18. Smuszkiewicz P, Trojanowska I, Tomczak H. Venous catheter microbiological monitoring. Necessity or a habit? Med Sci Monitor 2009; 15: SC5-8.

19. Eames T, Grabein B, Kroth J, Wollenberg A. Microbiological analysis of epidermal growth factor receptor inhibitor therapy-associated paronychia. JEADV 2010; 24: 958-60.

20. Tomczak H, Dańczak-Pazdrowska A, Horla A, et al. Estimation of vancomycin MIC for Staphylococcus aureus in patients treated in the Chair and Department of Dermatology, Poznan University of Medical Sciences. Postep Derm Alergol 2011; 28: 462-6. 